\title{
Comparison of immunological detection of 5- hydroxytryptamine by monoclonal antibodies with standard silver stains as an aid to diagnosing carcinoid tumours
}

\author{
P A V SHAW \\ From the Department of Histopathology, Leicester Royal Infirmary, Leicester
}

SUMMARY Immunoreactivity to a monoclonal antibody against 5-hydroxytryptamine (5HT) was compared with Churukian Schenk argyrophilia and Masson Fontana argentaffin staining as an aid to the diagnosis of 53 carcinoid tumours. Thirty four tumours were argentaffin positive, 50 were argyrophil positive, and 43 contained immunologically detectable 5HT. In general, argentaffin staining and immunological detection of 5HT failed to pick up tumours derived from the foregut of type B or type D morphology. Argentaffin negative tumours usually showed only focal immunoreactivity for 5HT. If immunological detection of 5HT is used alone as a marker for carcinoid tumours problems arise in the differentiation of carcinoid tumours from adenocarcinomas which may also contain 5HT. These results were compared with those culled from other reported techniques used as an aid to the diagnosis of carcinoid tumours.

Neuroendocrine tumours associated with the gut were described in the early 20th century, although their true nature was not recognised. In 1907 Oberndorfer labelled them "karzinoide tumoren", a name which, in its English translation as carcinoid tumours, has been in widespread use ever since.

Despite the fact that many carcinoid tumours appear to infiltrate diffusely surrounding tissues they often behave much less aggressively than adenocarcinomas and as a result have a much better prognosis. ${ }^{23}$ Moreover, these tumours are often associated with symptoms related to excessive or inappropriate release of hormones. ${ }^{24}$ Although the morphology of most types of carcinoid tumours is distinctive and the diagnosis is usually strongly suspected before special stains are used, it can be variable. Some tumours, especially the less well differentiated or mucinous types, can present a diagnostic problem, ${ }^{56}$ and it is in these cases that further investigations are needed. ${ }^{7}$

Until recently the stains used routinely for confirmation of the diagnosis of carcinoid tumour were of the argyrophil, argentaffin, or diazo types. The success of argentaffin and diazo, however, depends on the presence of large amounts of 5-hydroxytryptamine

Accepted for publication 6 October 1987
(5HT) within the tumour cells, and the argyrophil methods are not entirely specific. ${ }^{85}$ Over the past few years immunocytochemical techniques have become more widespread in routine laboratories, and it has been suggested that immunocytochemical localisation of 5HT "provides a simpler, more reliable procedure for the diagnosis of carcinoid tumours".'

This study was undertaken to investigate that claim in a routine laboratory setting, paying special attention to subgroups of carcinoid tumours that may cause diagnostic difficulty and including in the series other neuroendocrine and non-neuroendocrine tumours.

\section{Material and methods}

A search was made of the files of the histopathology departments of the Leicester Royal Infirmary and Leicester General Hospital. All specimens diagnosed as carcinoid tumours from April 1981 until January 1986 (the period for which computer records were available) were included in the series. Further searches were made to identify other neuroendocrine tumours. Where adequate tissue was available one or two blocks from each specimen were recut and sections were stained as detailed below. All tissues had undergone fixation for 12 to 36 hours in unbuffered formalin before routine processing and paraffin embedding. 


\section{STAINING}

The sections were stained with haematoxylin and eosin, an argyrophil stain, an argentaffin stain, immunocytochemistry for 5HT, and where appropriate, periodic acid Schiff-diastase to show mucin. The method of Churukian and Schenk was used as the argyrophil stain; this is now used as a routine method in Leicester and has been reported to be more sensitive than other argyrophil stains. ${ }^{10}$ The reaction conditions differ from other argyrophil techniques but the method is similar to, and no more difficult than, a standard Grimelius stain. The standard Masson-Fontana technique was used for the argentaffin reaction.

\section{IMMUNOCYTOCHEMISTRY}

The technique used was an indirect immunoperoxidase method similar to that previously described. ${ }^{911}$ The primary antibody was a commercially available rat monoclonal (YC5/45 Seralab Ltd) which has been well characterised..$^{12}{ }^{13}$ It is directed against a formaldehyde condensation derivative of 5HT rather than 5HT itself and is therefore not suitable for use with material which has not been exposed to formalin or formaldehyde vapour. The sections were dewaxed, rehydrated, and endogenous peroxidase was blocked with acidified methanol. To reduce background staining they were preincubated with normal rabbit serum. The primary antibody was applied diluted 1 in 500 in phosphate buffered saline (PBS) and incubated overnight at $4^{\circ} \mathrm{C}$. After washing with several changes of PBS the rabbit antirat HRP conjugated secondary antibody (Miles), diluted 1 in 50 in PBS, was applied at room temperature. The sections were washed and the peroxidase localised using the diaminobenzidine hydrogen peroxide reaction.

Enterochromaffin cells were present in many sections and acted as internal positive controls; otherwise normal ileum was used as a positive control. Negative

Table 1 Details of patients with carcinoid tumours broken down by site of tumour

\begin{tabular}{lrlrl}
\hline $\begin{array}{l}\text { Site } \\
\text { of tumour }\end{array}$ & No & $\begin{array}{l}\text { Average } \\
\text { age }\end{array}$ & $\begin{array}{l}\text { M:F } \\
\text { ratio }\end{array}$ & $\begin{array}{l}\text { No with } \\
\text { metastases }\end{array}$ \\
\hline $\begin{array}{l}\text { All foregut: } \\
\quad \text { Upper }\end{array}$ & 17 & $53 \cdot 1$ & $8: 9$ & 4 \\
$\quad \begin{array}{l}\text { gastrointestinal tract } \\
\text { Bronchi }\end{array}$ & 5 & $54 \cdot 8$ & $2: 3$ & 1 \\
$\quad 11$ & $53 \cdot 3$ & $5: 6$ & 3 \\
Other & 1 & & $0: 1$ & 0 \\
$\quad$ Appendix & 36 & $42 \cdot 5$ & $9: 28$ & 6 \\
$\quad$ Small bowel & 28 & $32 \cdot 9$ & $9: 19$ & 2 \\
$\quad$ Caecum & 9 & $70 \cdot 2$ & $0: 9$ & 5 \\
Hindgut & 1 & $81 \cdot 0$ & $0: 1$ & 1 \\
Origin unknown & 1 & $64 \cdot 0$ & $1: 0$ & 0 \\
All sites & 4 & $62 \cdot 5$ & $3: 1$ & 4 \\
\hline
\end{tabular}

controls were performed, substituting either PBS or non-immune rat serum for the primary antibody.

\section{MOR PHOLOGY}

The carcinoids were morphologically classified using the scheme suggested by Dawson. ${ }^{5}$ Briefly, this scheme divides carcinoid tumours into five types:

Type $A$ consists of cords and large nests or plates of cells with a peripheral rim of smaller cells

Type $B$ has a well defined trabecular or ribbon pattern, forming straight or curved lines or loops, one or two layers thick lying on a thin connective tussue stroma.

Type $C$ is rare in its pure form which has a tubuloacinar structure with periodic acid Schiff positive extracellular material.

Type $D$ usually consists of undifferentiated or oat-like cells with no characteristic pattern, often with areas of necrosis.

Type E ("Fifth" type of Dawson) has a mixed pattern of type A areas with gland formation and cells showing both intracellular mucin and neuroendocrine features.

The peroxidase reaction was assessed for both intensity and number of cells reacting. Intensity was assessed by comparison with enterochromaffin cells using a five point scale of 0 to 4 . Any staining greater than 1 was regarded as positive. If less than $10 \%$ of cells in a tumour were positive this was recorded.

\section{OTHER TISSUES}

Other neuroendocrine material apart from carcinoid tumours which were tested included oat cell carcinomas, phaeochromocytomas, a medullary carcinoma of thyroid and a paraganglioma.

In an effort to provide suitable non-neuroendocrine tumours to act as negative controls a selection of primary and secondary tumours from the gastrointestinal tract, which had posed diagnostic difficulty were tested. In all these cases electron microscopical examination had been performed and a reliable diagnosis had eventually been made. This latter group comprised lymphomas, malignant melanomas, and poorly differentiated carcinomas. A small number of obvious adenocarcinomas of gastrointestinal tract origin were also included.

\section{Results}

Fifty nine surgical and two necropsy cases of tumours previously diagnosed as carcinoid tumours were identified from the records. All these tumours were included in the study on the basis of their morphology 
Table 2 Morphology of carcinoid tumours broken down by site (figures in parentheses are No \%)

\begin{tabular}{|c|c|c|c|c|c|c|}
\hline \multirow{2}{*}{$\begin{array}{l}\text { Site } \\
\text { of } \\
\text { tumor }\end{array}$} & \multicolumn{5}{|c|}{ Morphology } & \multirow[b]{2}{*}{ Total } \\
\hline & $A$ & $B$ & $C$ & $D$ & $E$ & \\
\hline All foregut: & $4(17)$ & $14(58)$ & 0 & $6(25)$ & 0 & 24 \\
\hline $\begin{array}{l}\text { Upper } \\
\text { gastrointestinal } \\
\text { tract }\end{array}$ & 1 & 5 & 0 & & 0 & 7 \\
\hline Bronchi & 2 & 9 & 0 & 5 & 0 & 15 \\
\hline Other & 1 & 0 & 0 & 0 & 0 & 1 \\
\hline All midgut: & $30(81)$ & 1 (3) & $1(3)$ & 0 & $5(14)$ & 37 \\
\hline Appendix & 22 & 0 & 100 & 0 & 5 & 28 \\
\hline Small bowel & 9 & 1 & 0 & 0 & 0 & 10 \\
\hline Caecum & 1 & 0 & 0 & 0 & 0 & 1 \\
\hline Hindgut & 0 & 0 & 0 & 1 & 0 & i \\
\hline Origin unknown & 1 & 0 & 0 & 3 & 0 & 4 \\
\hline All sites & $35(53)$ & $15(23)$ & $1(2)$ & $10(15)$ & $5(8)$ & 66 \\
\hline
\end{tabular}

alone, although the previous diagnosis was often made with the help of special stains. The 61 cases included three repeat specimens with appearances identical with those of the initial biopsy specimens. The details of the 58 patients are recorded in table 1 . In two cases tumur was present in both ileum and appendix with no clear site of origin.

\section{MORPHOLOGY}

On histological examination eight of the tumours contained two distinct morphologies giving a total of 66 individual areas which were assessed by silver and immunocytochemical staining (table 2). Generally, there was little difficulty in allocating a tumour to a particular histological type apart from one specimen, allocated to type A, with an acinar morphology but with negative periodic acid Schiff staining. Seven of the biphasic tumours were derived from the foregut and were either predominantly type $D$ with a small area of type B or predominantly type B with a small area of type $A$. The other biphasic tumour originated from the ileum where there was a small area of type B in a predominantly type $\mathrm{A}$ tumour.

There were 14 cases with histologically confirmed metastases including one from the stomach, three bronchial, five ileal (two with appendiceal disease), one hindgut tumour and the four tumours with no identifiable primary site. Two of these tumours were biphasic giving a total of 16 morphological areasseven type $A$, two type $B$, and seven type $D$.

Insufficient material was available for further analysis in five specimens (three type $A$ and one type $E$ from the appendix and a bronchial biopsy specimen of type D). The staining characteristics of the remaining 53 tumours are recorded in table 3 , and the corresponding 61 areas in table 4. All controls stained appropriately.

\section{ARGYROPHIL AND ARGENTAFFIN STAINS}

The argyrophil stain was negative in only four cases. Two tumours were of type D morphology, one a metastasis in a lymph node (which stained equivocally), and one bronchial carcinoid. Both showed neurosecretory granules on electron microscopical examination. The third was a type A tumour from strangulated, necrotic ileum, and the fourth was a bronchial adenoma showing obvious type B morphology with a small area of type A. No electron microscopical examination was performed on this last specimen. Many of the foregut tumours, besides showing diffuse positive staining, contained occasional cells with a much more intense staining reaction. Both the argentaffin and argyrophil staining were most intense at the periphery of tumour islands with often little central staining.

\section{IMMUNOHISTOCHEMISTRY}

A diffuse background staining was often seen in tumours which was more prominent than that seen in control sections; the positive cells usually had a strong granular cytoplasmic reaction obviously distinguishable from background (fig 1). Invariably where the argentaffin reaction was present $5 \mathrm{HT}$ could be shown immunohistochemically, although in many cases the reaction was less noticeable and less distinct than in both silver stains. The unreactive areas were often within larger specimens where fixation had been delayed. In a small number of cases, rather than the reaction product being concentrated at the periphery of cell islands as in the silver stains, there was a more homogeneous reaction throughout the cell group with only slight accentuation at the periphery (fig 2).

In almost all the cases in which 5HT was detected

Table 3 Nos of carcinoid tumours reacting positively for each method broken down by site (percentages in parentheses)

\begin{tabular}{|c|c|c|c|c|}
\hline Site of tumour & Total & Argyrophil & Masson Fontana & Anti-5HT \\
\hline $\begin{array}{l}\text { All foregut: } \\
\text { Upper gastrointestinal tract } \\
\text { Bronchi } \\
\text { Other } \\
\text { All midgut: } \\
\text { Appendix } \\
\text { Small bowel } \\
\text { Caecum } \\
\text { Hindgut } \\
\text { Origin unknown } \\
\text { All sites }\end{array}$ & $\begin{array}{r}16 \\
5 \\
10 \\
1 \\
32 \\
24 \\
9 \\
1 \\
1 \\
4 \\
53\end{array}$ & $\begin{aligned} & 14(88) \\
& 5 \\
& 8 \\
& 1 \\
& 1 \\
& 32(100) \\
& 24 \\
& 8 \\
& 1 \\
& 1(100) \\
& 3(75) \\
& 50(94)\end{aligned}$ & $\begin{array}{rr}3 & (19) \\
2 & \\
0 & \\
1 & \\
30 & (94) \\
22 & \\
8 & \\
1 & \\
0 & (000) \\
1 & (25) \\
34 & (64)\end{array}$ & $\begin{array}{rr}9 & (56) \\
3 & \\
5 & \\
1 & \\
31 & (97) \\
23 & \\
8 & \\
1 & \\
1 & (100) \\
2 & (50) \\
43 & (81)\end{array}$ \\
\hline
\end{tabular}


Table 4 Nos of carcinoid tumours reacting positively with each method broken down by morphology (percentages in parentheses)

\begin{tabular}{lrrrr}
\hline $\begin{array}{l}\text { Morphology } \\
\text { of } \\
\text { tumour }\end{array}$ & Total & Argyrophil & $\begin{array}{l}\text { Masson } \\
\text { Fontana }\end{array}$ & Anti-5HT \\
\hline Type A & 32 & $31(97)$ & $29(91)$ & $29(91)$ \\
Type B & 15 & $14(93)$ & $2(13)$ & $8(53)$ \\
Type C & 1 & $1(100)$ & 0 & 0 \\
Type D & 9 & $7(78)$ & 0 & $4(45)$ \\
Type E & 4 & $4(100)$ & $3(75)$ & $4(100)$ \\
All types & 61 & $57(93)$ & $34(56)$ & $45(74)$ \\
\hline
\end{tabular}

but the argentaffin reaction was negative, less than $10 \%$ of cells within the tumour were immunopositive for 5HT. All tumours with a biphasic pattern showed identical patterns of reaction and staining in both morphological types.

In 10 patients samples were available from both primary tumour and metastases. In nine cases the staining pattern was identical in both primary and metastatic tumours. The remaining case had demonstrable 5HT and argyrophilia at both sites but the primary tumour was argentaffin positive and the metastasis argentaffin negative.

\section{OTHER TUMOURS}

Five non-carcinoid neuroendocrine tumours (three phaeochromocytomas, one chemodectoma, and one medullary carcinoma of thyroid) were included. All showed positive argyrophil staining although this was very weak in two of the three phaeochromocytomas. The phaeochromocytoma with the stronger argyrophil staining was also argentaffin positive but the other tumours were argentaffin negative. All five tumours were negative for 5HT.

Of eight oat cell carcinomas tested, only one showed a small number of cells positive for argyrophil stains and $5 \mathrm{HT}$. This tumour showed areas with a poorly formed trabecular pattern with orientated nuclei and occasional large cells with a lower nuclear:cytoplasmic ratio. These features suggest that this tumour falls into the grey area between oat cell carcinoma and carcinoid tumour, possibly representing a type D or "atypical" carcinoid.

Of the diagnostically difficult non-neuroendocrine tumours tested, all except one were negative on argyrophil and argentaffin staining with no 5HT detected. One tumour labelled as a moderate to poorly differentiated adenocarcinoma of large bowel, mostly comprising poorly formed glandular structures, contained groups of up to four cells positive for 5HT in the less well differentiated areas (fig 3). Similar positive cells were found on argyrophil but not argentaffin staining. No neurosecretory granules had been found in the small portion of this tumour submitted for electron microscopical examination.

\section{Discussion}

Although relatively small, this series of carcinoid tumours has a site incidence and age distribution similar to that of larger series. ${ }^{237}$ The numbers and distribution of the morphological types of carcinoid are also broadly in agreement with the findings of previous publications ${ }^{714}$ given the differences in classification of mucin containing tumours. ${ }^{57}$ In general, type $\mathrm{A}$ and type $\mathrm{E}$ tumours are found in structures derived from the midgut and type $B$ and type $D$ tumours in foregut and hindgut structures.

Of the three methods tested, Churukian-Schenk argyrophilia gave the highest pick up rate, up to $97 \%$ in one study, ${ }^{10} 94 \%$ in ours. It fails in poorly fixed tissue, in common with other argyrophil techniques. ${ }^{8}$ Although it has been said that argyrophil techniques are poor at identifying hindgut carcinoids ${ }^{7}$ the Churukian-Schenk method seems to be better at this than other argyrophil techniques. ${ }^{10}$

The Masson Fontana technique proved positive in the least number of tumours. It again fails in poorly fixed specimens and also in most foregut and hindgut derived tumours. ${ }^{714}$

Table 5 Collected results from previous studies to compare various staining methods (figures indicate percentage of carcinoid tumours positively staining)

\begin{tabular}{|c|c|c|c|c|c|}
\hline \multirow[b]{2}{*}{ Staining method } & \multicolumn{4}{|c|}{ Tumour site } & \multirow[b]{2}{*}{ References } \\
\hline & Foregut & Midgut & Hindgut & All & \\
\hline $\begin{array}{l}\text { Churukian-Schenk } \\
\text { Other argyrophil } \\
\text { Masson Fontana } \\
\text { Lead haematoxylin } \\
\text { Diazonium } \\
\text { Monoclonal anti-5HT } \\
\text { Polyclonal anti-5HT } \\
\text { Neuron specific enolase } \\
\text { Prealbumin } \\
\text { PGP 9.5 }\end{array}$ & $\begin{array}{r}92 \\
78 \\
20 \\
56 \\
3 \\
32 \\
45 \\
87 \\
73 \\
75\end{array}$ & $\begin{array}{l}98 \\
97 \\
81 \\
93 \\
78 \\
98 \\
84 \\
97 \\
98 \\
90\end{array}$ & $\begin{array}{r}100 \\
52 \\
13 \\
39 \\
0 \\
80 \\
14 \\
100 \\
67 \\
100\end{array}$ & $\begin{array}{l}96 \\
81 \\
44 \\
67 \\
44 \\
62 \\
34 \\
96 \\
86 \\
85\end{array}$ & $\begin{array}{l}10^{*} \\
4,7,9,10,14,17,22-29,33 \\
4,7,9,10,14,17,22,24-29,33^{*} \\
10 \\
10 \\
9,17^{*} \\
4,22,26,27 \\
24,30,31,32,33 \\
23 \\
32\end{array}$ \\
\hline
\end{tabular}

*Results from this paper. 

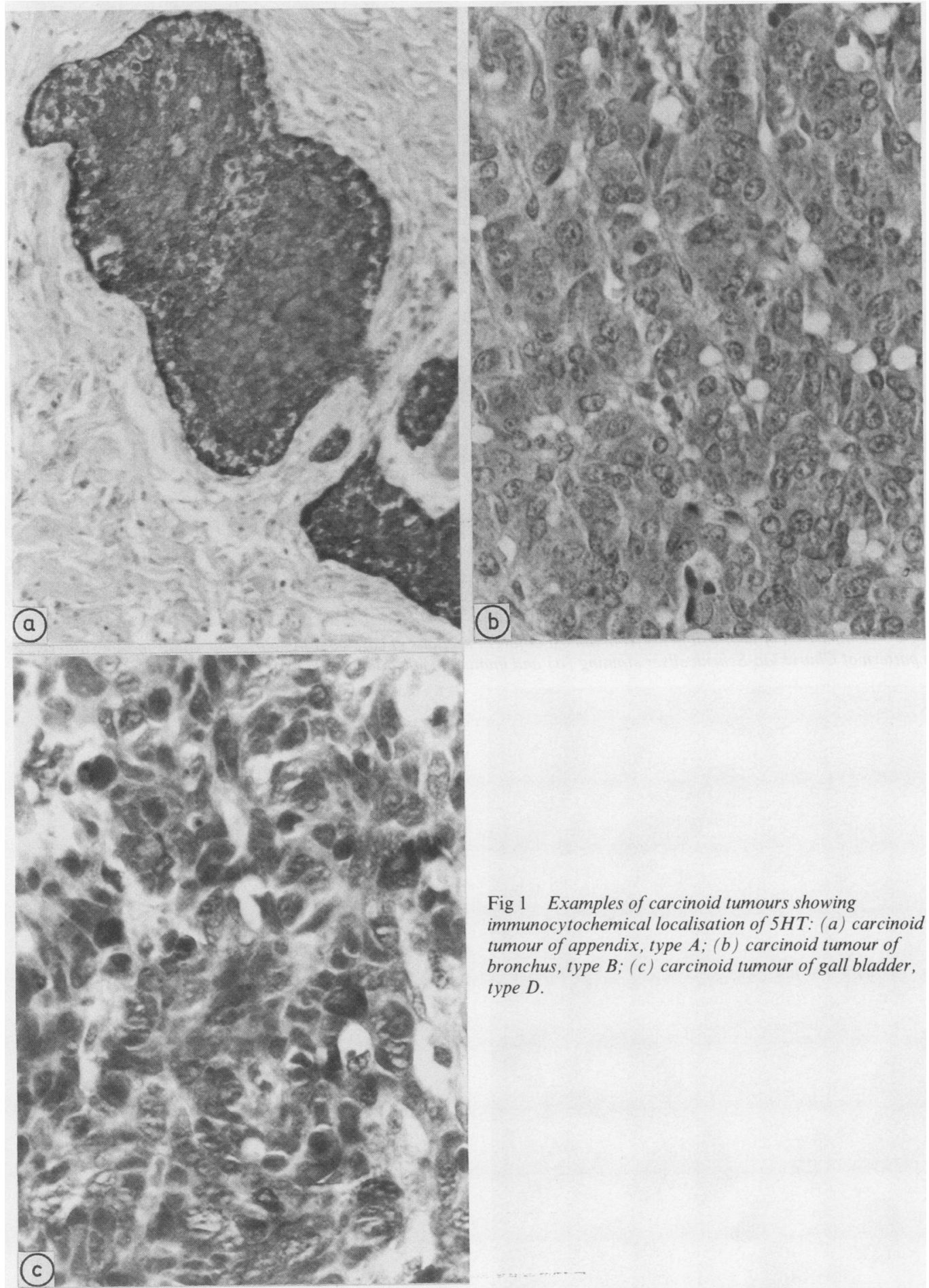

Fig 1 Examples of carcinoid tumours showing immunocytochemical localisation of 5HT: (a) carcinoid tumour of appendix, type $A$; (b) carcinoid tumour of bronchus, type $B ;(c)$ carcinoid tumour of gall bladder, type $D$. 


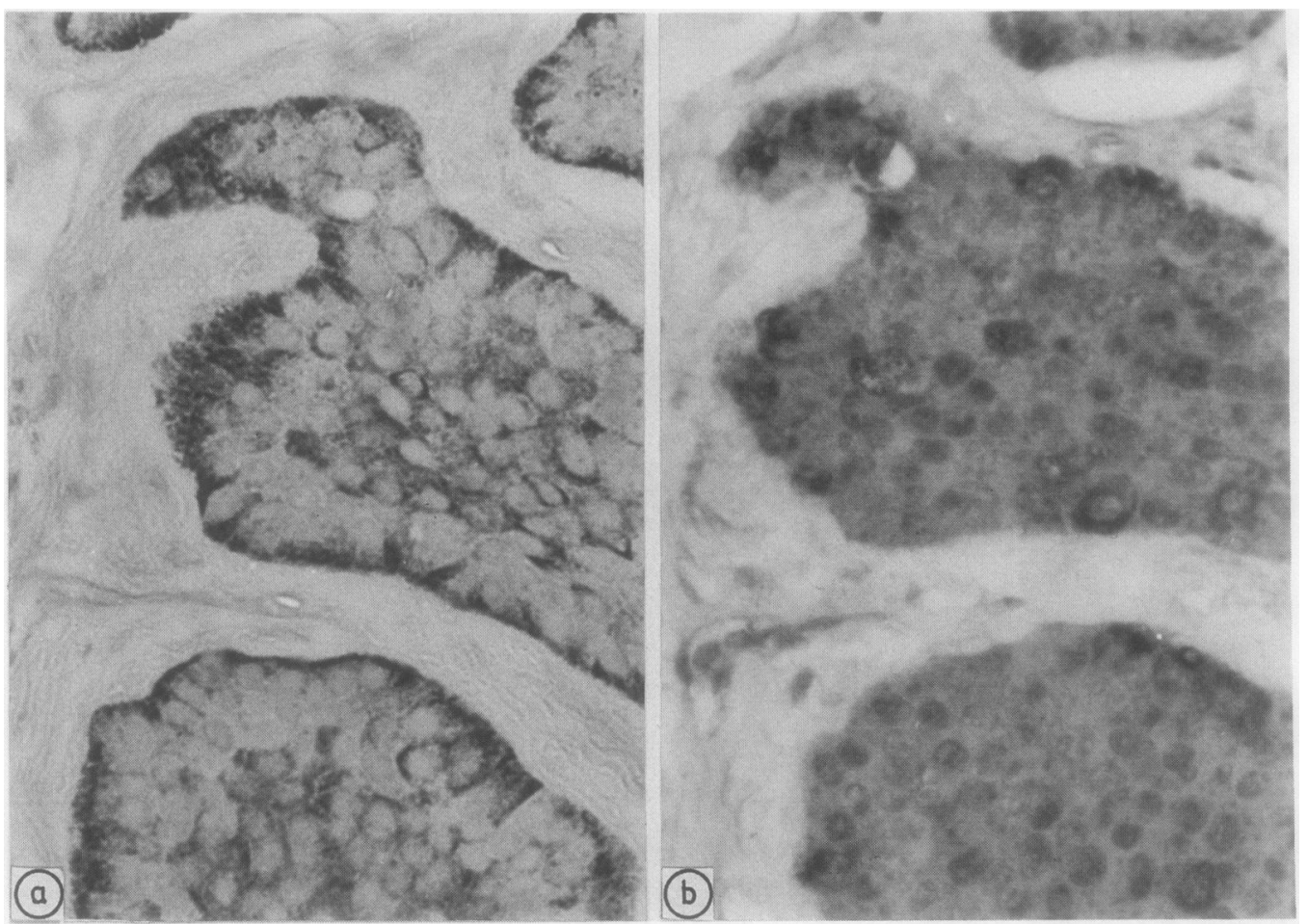

Fig 2 Comparison of identical fields from almost adjacent sections of carcinoid tumour of appendix to show differences in pattern of Churukian-Schenk silver staining (a) and immunolocalisation of $5 H T$ by YC5/45 (b).

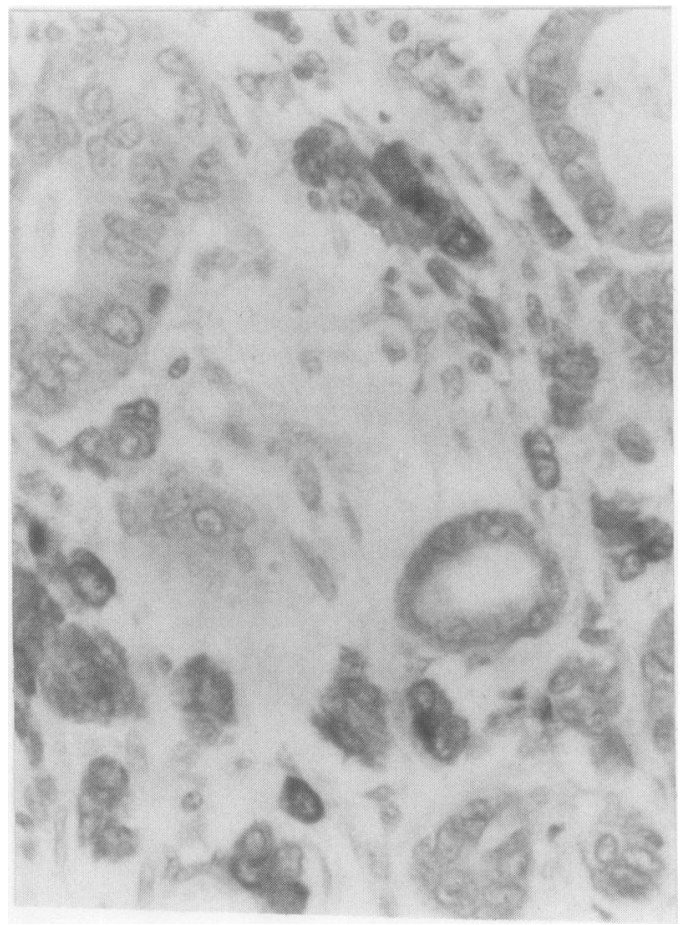

Fig 3 Otherwise typical adenocarcinoma of large bowel containing small group of cells immunoreactive for $5 H T$. 
The sensitivity of immunocytochemical detection of 5HT as a marker for carcinoid tumours lies somewhere between the two silver stains with an $81 \%$ pick up rate in this study. As found previously, ${ }^{9}$ the best results were in midgut tumours with fewer positive results in foregut and hindgut tumours.

As expected, ${ }^{7}$ there was no absolute correlation between site, staining pattern, and morphological subtype. In general terms, however, subtypes A and E are usually found in midgut tumours, stain positively with argentaffin methods, and are immunoreactive for 5HT. Subtypes B and D tend to be derived from foregut and hindgut structures, are not usually argentaffin positive, but $5 \mathrm{HT}$ can be detected in about half the foregut tumours. ${ }^{2}$ Only a small number of hindgut carcinoids have been tested, and further data are required before any general conclusions can be reached. Churukian Schenk argyrophilia is consistently present across the whole range of morphologies and sites.

It has been claimed that immunocytochemistry for 5HT has advantages over argyrophilia as an aid to the diagnosis of carcinoids due to its greater specificity. ${ }^{9}$ This study and another ${ }^{15}$ have shown that 5HT is focally detectable in otherwise unremarkable colonic adenocarcinomas, and focal 5HT has been found in non-endocrine gastric carcinomas. ${ }^{16}$ From these observations it can be seen that problems may arise when using these techniques to interpret the nature of tumours with only focal cells containing $5 \mathrm{HT}$. Thus it has been recommended that carcinoid tumour is diagnosed only when a high proportion of cells within a tumour show neuroendocrine features. In this study and others ${ }^{9}$ many tumours showed diffuse argyrophil positivity, confirming a diagnosis of carcinoid, but only focal immunoreactivity for $5 \mathrm{HT}$. If this latter method was used alone problems in interpretation could have arisen.

It has been recognised that argentaffin positivity does not always go hand in hand with immunodetectable 5HT in a particular cell, especially in the foregut, ${ }^{17}$ but also in other carcinoids. ${ }^{4}$ Similar discrepancies were noted in this study. These included the observations that immunologically detectable 5HT is present throughout the tumour islands, as opposed to the peripheral staining of both silver techniques, and also that less 5HT was present in the centre than at the periphery of larger tumours. The former observation is presumably due to the greater sensitivity of the immunological technique in detecting $5 \mathrm{HT}^{17}$ and the latter to the vulnerability of this technique to inadequate fixation.

A possible explanation for these observations is that a labile pool of 5HT exists in the cytoplasm of the cell, not just within neurosecretory granules, ${ }^{18}$ and it is perhaps this more immunologically accessible pool that is detected by immunocytochemistry. Serotonin when not confined to neurosecretory granules is a highly soluble substance and any delay in fixation, which conjugates and immobilises it to protein, may lead to the loss of this pool from the cell. Such a delay may explain the increased background staining in many specimens which could be due to the antibody detecting 5HT lost from the cells.

Many techniques have been suggested as being of use in the diagnosis of carcinoid tumours. These include histochemical methods such as argyrophil, argentaffin, lead haematoxylin and diazo techniques, immunocytochemical methods with antibodies to serotonin, neuron specific enolase (NSE), prealbumin, PGP 9.5 and many peptide hormones, and electron microscopy.

A good diagnostic screening test would use easily obtainable reagents, be easily performed in routine laboratories, and be quick, cheap, sensitive and specific. This perfect method does not exist and it is inevitable that compromises have to be made. Reagents for all the above methods are available commercially. Electron microscopy would be useful in many cases but suitable tissue is not always available and some centres do not have routine access to such equipment. Many laboratories now have facilities for immunocytochemistry, however, and the other methods pose no particular problems.

The time taken for each method varies. In this study incubation overnight was used but this has been reduced to four hours with little apparent loss of sensitivity. ${ }^{9}$ This means that all the methods mentioned can be performed within one day and some of the histochemical methods, in particular, can be performed in a few hours.

Some reported results of each method over the past 15 years are summarised in table 5 . These were all retrospective studies and used selected material in which carcinoid tumour was diagnosed by other criteria, usually morphological, so these series give neither the true sensitivity nor the true specificity of a particular method. Cases may be duplicated and methods vary slightly. Moreover, in many studies a tumour was considered to be positive even if only a few cells were reactive. As mentioned above, this could cause problems in interpretation and may lead to a decrease in the diagnostic sensitivity.

There is a need for prospective studies to be done on a wide range of material to get a clear idea of each method's efficacy. It is often only in routine work that some have been found to have inadequate specificity for diagnostic use - as has been suggested for immunolocalisation with NSE. ${ }^{19}$ Conversely, the tumours which do not conform to the usual morphological criteria are often not even investigated with special stains, the diagnosis of carcinoid not being suspected. 
These caveats taken into consideration, table 5 shows that the immunocytochemical demonstration of NSE and the Churukian-Schenk argyrophil stain identify the greatest number of carcinoid tumours. Both score over other methods in their ability to identify hindgut carcinoids. Doubts on the specificity of both methods, however, have been expressed. The use of antibodies to prealbumin and PGP 9.5 has potential but experience is limited. Of the other argyrophil methods, the Grimelius stain seems to be more sensitive and has been well tried. There is no advantage, except perhaps one of cost, in using the Masson Fontana or diazo reactions to show 5HT, as immunocytochemical methods are more sensitive and more specific. ${ }^{81213}$

Either the immunocytochemical demonstration of NSE or Churukian Schenk argyrophil staining seems to be useful as an initial screening test. Both identify most carcinoids, but confirmation of the diagnosis requires identification of secretory products within cells either by specific antisera or electron microscopy. It is in this secondary role that immunocytochemical detection of 5HT would find its place as it is not diagnostically sensitive enough to use alone as confirmation of the neuroendocrine nature of a tumour.

I thank Dr Rosemary A Walker for helpful comments and advice, Paul Sanderson for technical assistance with the silver stains, and Mrs G Holmes for typing the manuscript.

\section{References}

1 Oberndorfer S. Karzinoide tumoren des dunndarms. Frankfurter Zeitschrift für Pathologie 1907;1:426-32.

2 Sanders FJ, Axtell HK. Carcinoids of the gastrointestinal tract. Surg Gynecol Obstet 1964;119:369-80.

3 Godwin JD. Carcinoid tumours,. An analysis of 2837 cases. Cancer 1975;36:560-9.

4 Yang $\mathrm{K}$, Ulich T, Cheng L, Lewin KJ. The neuroendocrine products of intestinal carcinoids. Cancer 1983;51:1918-26.

5 Dawson IMP. Diffuse endocrine and neuroendocrine cell tumours. In: Anthony PP, Macsween RNM, eds. Recent advances in histopathology. Vol. 12. Edinburgh: Churchill Livingston, 1984:111-28.

6 Klein HZ. Mucinous carcinoid tumor of the vermiform appendix. Cancer 1974;33:770-7.

7 Jones RA, Dawson IMP. Morphology and staining patterns of endocrine cell tumours in the gut, pancreas and bronchus and their possible significance. Histopathology 1977;1:137-50.

8 Pearse AGE. Histochemistry, theoretical and applied. 4th ed. Edinburgh: Churchill Livingston, 1985.

9 Wells CA, Taylor SM, Cuello AC. Argentaffin and argyrophil reactions and serotonin content of endocrine tumours. $J$ Clin Pathol 1985;38:49-53.

10 Smith DM Jr, Haggitt RC. A comparative study of generic stains for carcinoid secretory granules. Am J Surg Pathol 1983;7:61-8.

11 Cuello AC, Wells C, Chaplin AJ, Milstein C. Serotonin immunoreactivity in carcinoid tumours demonstrated by a monoclonal antibody. Lancet 1982; i:771-3.

12 Consalazione A, Milstein C, Wright B, Cuello AC. Immunocyto- chemical detection of serotonin with monoclonal antibodies. $J$ Histochem Cytochem 1981;29:1425-30.

13 Milstein C, Wright B, Cuello AC. The discrepancy between the cross reactivity of a monoclonal antibody to serotonin and its immunochemical specificity. Mol Immunol 1983;20:113-23.

14 Soga J, Tazawa K. Pathologic analysis of carcinoids. Histologic reevaluation of 62 cases. Cancer $1971 ; 28: 990-8$.

15 Arends JW, Wiggers T, Verstijnen K, Bosman FT. The occurrence and clinicopathological significance of serotonin immunoreactive cells in large bowel carcinoma. J Pathol 1986;149:97-102.

16 Lei D-N, Elias JM. The detection of serotonin in gastric carcinoma. Am J Clin Pathol 1983;80:436-40.

17 Wilander E, Lundqvist M, El-Salhy $\mathbf{M}$. Serotonin in foregut carcinoids. A survey of 60 cases with regard to silver stains, formalin induced fluorescence and serotonin immunochemistry. J Pathol 1985;148:251-8.

18 Nilsson O, Ericson LE, Dahlstrom A, Ekholm R, Steinbusch HWM, Ahlman H. Subcellular localization of serotonin immunoreactivity in rat enterochromaffin cells. Histochemistry 1985;82:351-5.

19 Schemchel DE. Gamma subunit of the glycolytic enzyme enolase nonspecific or neuron specific? Lab Invest 1985;52:239-42.

20 Moertel CG, Dockerty MB, Judd ES. Carcinoid tumours of the vermiform appendix. Cancer 1968;21:270-8.

21 Azzopardi JG, Pollack DJ. Argentaffin and argyrophil cells in gastric carcinoma. J Pathol Bacteriol 1963;86:443-51.

22 Bosman FT, Brutel de la Riviere A, Giard RWM, Verhofstad AAJ, Cramer-Knijnenberg G. Amine and peptide hormone production by lung carcinoid: a clinicopathological and immunocytochemical study. J Clin Pathol 1984;37:931-6.

23 Miller ID, Reid WA, Liddle CN, Horne CHW. Immunolocalization of prealbumin as a marker for carcinoid tumours. $J$ Pathol 1984;143:199-204.

24 Sheppard MN, Corrin B, Bennett MH, Marangos PJ, Bloom SR, Polak JM. Immunocytochemical localization of neuron specific enolase in small cell carcinomas and carcinoid tumours of the lung. Histopathology 1984;8:171-81.

25 Wilander E, Grimelius L, Lundqvist G, Skoog V. Polypeptide hormones in argentaffin and argyrophil gastroduodenal endocrine tumours. Am J Pathol 1979;96:519-26.

26 Taxy JB, Mendelsohn G, Gupta PK. Carcinoid tumours of the rectum. Silver reactions, fluorescence and serotonin content of cytoplasmic granules. Am J Clin Pathol 1980;74:791-5.

27 Alumets J, Alm P, Falkmer S, et al. Immunohistochemica evidence of peptide hormones in endocrine tumours of rectum Cancer 1981;48:2409-15.

28 Wilander E, Portela-Gomes G, Grimelius L, Westermak P Argentaffin and argyrophil reactions of human gastrointestinal carcinoids. Gastroenterol 1977;73:733-6.

29 Wilander E, El-Salhy M, Pitkanen P. Histopathology of gastric carcinoids: a survey of 42 cases. Histopathology 1984;8:183-93.

30 Simpson S, Vinik AI, Marangos PJ, Lloyd RV. Immunohistochemical localization of neuron specific enolase in gastropancreatic neuroendocrine tumours. Cancer 1984;54:1364-99.

31 Tapia FJ, Polak JM, Barbosa AJA, et al. Neuron specific enolase is produced by neuroendocrine tumours. Lancet $1981 ;$; :808-11.

32 Rode J, Dhillon AP, Doran JF, Jackson P, Thompson RJ. PGP 9.5, a new marker for human neuroendocrine tumours. Histopathology 1985;9:147-58.

33 Lundqvist M, Wilander E, Esscher T, Palham S. Neuron specific enolase in mucosal endocrine cells and carcinoid tumours of the small intestine: a comparative study with neuron specific enolase immunocytochemistry and silver stains. Histochem $J$ 1985;17:323-31.

Requests for reprints to: Dr P A V Shaw, Department of Histopathology, Leicester Royal Infirmary, Leicester LE1 5WW, England. 